\title{
Divergence Between Sympatric Rice- and Maize-Infecting Populations of Rhizoctonia solani AG-1 IA from Latin America
}

\author{
A. D. González-Vera, J. Bernardes-de-Assis, M. Zala, B. A. McDonald, \\ F. Correa-Victoria, E. J. Graterol-Matute, and P. C. Ceresini
}

First and sixth authors: DANAC-Fundación para la Investigación Agrícola, Laboratorio de Protección Vegetal, San Javier, Yaracuy/Universidad Central de Venezuela, Facultad de Agronomía, Maracay, Aragua, Venezuela; second, third, fourth, and seventh authors: ETH Zurich—Swiss Federal Institute of Technology, Plant Pathology, Institute of Integrative Biology (IBZ), Universitaetstrasse 2, LFW B28, 8092 Zurich, Switzerland; fifth author: RiceTec, Inc., P.O. Box 1305, Alvin, TX 77512; and seventh author: Universidade Estadual Paulista-UNESP, Departamento de Fitossanidade, Engenharia Rural e Solos, 15385-000, Campus de Ilha Solteira, São Paulo, Brazil.

Accepted for publication 30 September 2009.

\begin{abstract}
González-Vera, A. D., Bernardes-de-Assis, J., Zala, M., McDonald, B. A., Correa-Victoria, F., Graterol-Matute, E. J., and Ceresini, P. C. 2010. Divergence between sympatric rice- and maize-infecting populations of Rhizoctonia solani AG-1 IA from Latin America. Phytopathology 100:172-182.

The basidiomycetous fungus Rhizoctonia solani anastomosis group (AG)-1 IA is a major pathogen in Latin America causing sheath blight (SB) of rice. Particularly in Venezuela, the fungus also causes banded leaf and sheath blight (BLSB) on maize, which is considered an emerging disease problem where maize replaced traditional rice-cropping areas or is now planted in adjacent fields. Our goals in this study were to elucidate (i) the effects of host specialization on gene flow between sympatric and allopatric rice and maize-infecting fungal populations and (ii) the reproductive mode of the fungus, looking for evidence of recombination. In total, 375 isolates of $R$. solani AG1 IA sampled from three sympatric rice and maize fields in Venezuela (Portuguesa State) and two allopatric rice fields from Colombia (Meta State) and Panama (Chiriquí State) were

genotyped using 10 microsatellite loci. Allopatric populations from Venezuela, Colombia, and Panama were significantly differentiated $\left(\Phi_{\mathrm{ST}}\right.$ of 0.16 to 0.34 ). Partitioning of the genetic diversity indicated differentiation between sympatric populations from different host species, with $17 \%$ of the total genetic variation distributed between hosts while only 3 to $6 \%$ was distributed geographically among the sympatric Venezuelan fields. We detected symmetrical historical migration between the riceand the maize-infecting populations from Venezuela. Rice- and maizederived isolates were able to infect both rice and maize but were more aggressive on their original hosts, consistent with host specialization. Because the maize- and rice-infecting populations are still crosspathogenic, we postulate that the genetic differentiation was relatively recent and mediated via a host shift. An isolation with migration analysis indicated that the maize-infecting population diverged from the riceinfecting population between 40 and 240 years ago. Our findings also suggest that maize-infecting populations have a mainly recombining reproductive system whereas the rice-infecting populations have a mixed reproductive system in Latin America.
\end{abstract}

Anastomosis group (AG)-1 of the anamorphic basidiomycetous fungus Rhizoctonia solani Kühn is a major pathogen on important Poaceae staple crops worldwide, including rice and maize $(33,53,54)$. The distinction among subgroups within AG-1 (called IA, IB, IC, ID, IE, and IF) is based upon the anastomosis criterion, colony morphology, type of sclerotia produced, and pathogenicity differences $(50,62)$. Ribosomal DNA sequence data support the distinction among the six AG-1 subgroups as phylogenetic species $(21,23)$.

The fungus causes sheath blight (SB) of rice and banded leaf and sheath blight (BLSB) on maize $(33,53,54)$. Both leaf and sheath blight diseases already have a worldwide importance but BLSB is considered to be an emerging disease problem in Asia (Bhutan, India, Indonesia, Nepal, Philippines, southern China, Vietnam), Africa, and Latin America $(53,54,73)$.

In Latin America, BLSB may become a constraint to maize production as the use of maize in rice-cropping systems increases

Corresponding author: P. Ceresini; E-mail address: paulo.ceresini@agrl.ethz.ch

The first and the second authors have made equal contributions to this study.

* The $\boldsymbol{e}$-Xtra logo stands for "electronic extra" and indicates that the online version contains two figures and two tables not available in the print version.

doi:10.1094/PHYTO-100-2-0172

(C) 2010 The American Phytopathological Society
(54). This appears to be the case in Venezuela, where maize replaced traditional rice-cropping areas or is now planted in adjacent fields $(12,13,54)$. In Venezuela, BLSB and SB are currently considered the first and second most important diseases of maize and rice crops, respectively $(12,13)$. The average yield losses caused by the fungus in Venezuela were reported to reach $30 \%$ in states such as Portuguesa, where warm and humid environmental conditions are favorable for the pathogen (12). Maize in Venezuela is mainly a rain-fed crop produced between May and October, whereas rice is cropped year round under irrigation (20).

Rice was introduced into Venezuela's Llanos grasslands by Spanish settlers during colonial times $(\approx 1,550)$ but rice cropping was not important until the 1940s. With support from two government subsidy programs (Plan de Fomento Arrocero, in 1931, and Plan Arrocero de la Corporación Venezolana de Fomento, in 1949) (67), the area planted to rice increased from 36 to 4,106 ha $(44,45)$ from 1937 to 1950 . By 2001, the ricecropping area in Portuguesa State expanded to 71,995 ha, representing $51.2 \%$ of total rice production in Venezuela (31). Although rice cropping is recent, archaeological evidence indicates that maize was grown by indigenous tribes on the shores of the Orinoco River in the Venezuelan Guayana region $(66,67)$. In 1937, maize cropping in Portuguesa State was significantly higher than rice, with maize planted on a total of 9,125 ha (44). By 2001, the area planted to maize reached 185,339 ha (31), representing 
$40.3 \%$ of Venezuela's maize production. Maize cropping is currently three times larger than rice and has expanded to areas formerly cropped with rain-fed upland rice. Although maize has been cultivated for much longer than rice in Venezuela, the Rhizoctonia diseases on maize occurred very recently. Rice sheath blight was first reported in Venezuela in 1949, a few years after the introduction of the first rice cultivars from the United States (39). However, the first report of BLSB on maize was in 1995, also in Portuguesa State (12).

The disease biology and dispersal ecology of $R$. solani AG-1 on Poacea has been extensively studied. In general, the Poaceaeinfecting $R$. solani AG-1 IA survives as mycelium and sclerotia in soil and on seed (50). Recurring disease cycles increase natural inoculum in the soil (50). Sharing of planting and harvesting equipment between rice- and maize-cropping areas is common in Venezuela (22); hence, their role in inoculum dispersal among rice and maize fields is likely to be important. The dispersal of inoculum associated with common weeds infected by the pathogen may also have played a role in spreading the pathogen between the two crops. Several exotic perennial Poaceae weed species that have invaded rice and maize fields in Venezuela are susceptible to $R$. solani AG-1 IA (e.g., Rottboelia exaltata L.f., Ischaemun rugosum Salisb, Cynodon dactylon (L.) Pers., Sorghum verticilliflorum (Steud.) Stapf, and S. halepense (L.) Pers.) (11).

Knowledge of the reproductive mode of Rhizoctonia solani AG-1 IA has just started to accumulate $(6,38,59)$. The fungus was thought to be predominantly asexual (50). Although basidiospore formation in paddy rice has been frequently observed, the role of sexual spores in the disease cycle is not fully understood $(33,47,51)$. When the sexual stage (teleomorph $=$ Thanatephorus cucumeris Frank Donk) is formed, meiospores (i.e., basidiospores) are assumed to have limited dispersal and to be of little or no importance in the disease epidemiology (47). However, sexual spores produced as a result of heterothallic mating might constitute an important aspect of the fungal life history that contributes to the genetic diversity of field populations of $R$. solani AG-1 IA on Poaceae. Analysis of the variation found for neutral markers in field populations supports this assertion. A mixed model of population structure that includes both recombination and clonality was indicated for $R$. solani AG-1 IA of rice in Texas (59), Louisiana (6), India (38), and China $(7,8)$. The role of the sexual stage in the epidemiology of maize-infecting populations of $R$. solani AG-1 IA is presently unknown, because infection by basidiospores has not been reported.

There is currently no information available regarding the population genetic structure of $R$. solani AG-1 IA infecting rice and maize in Latin America. Information on the extent of genetic differentiation and host specialization between rice- and maizeinfecting populations of $R$. solani AG-1 IA also is lacking. Host specialization has been detected within the $R$. solani complex (14) and, specifically, for AG-1 IA (6). Host specialization can lead to divergence between populations of plant pathogens (52). To infer whether host specialization is the main cause for the divergence, it is necessary to sample sympatric host populations to determine the extent of genetic differentiation. Cross-inoculation tests are also needed to determine the extent of host specialization. Analysis of the distribution of genetic diversity within and among distinct sympatric host-specific populations of the fungus could be used to identify patterns of between-host migration and to reveal recombination, with possible implications for the effectiveness of control strategies on both hosts (41).

Our goal in this study was to elucidate the population structure of the rice- and maize-infecting $R$. solani AG-1 IA pathosystem in Latin America. We sampled sympatric rice- and maize-infecting populations in Venezuela and two allopatric rice-infecting populations from Colombia and Panama. We focused on two main aspects of the system: (i) the effect of host specialization on gene flow between rice- and maize-infecting fungal populations and (ii) the reproductive mode of the fungus, looking for evidence of recombination within each field population. We tested the hypotheses of (i) no genetic differentiation between sympatric or allopatric rice- and maize-infecting populations and (ii) no differences in aggressiveness between rice- and maize-derived isolates. Our null hypothesis was that no differences would exist among the pathogen populations obtained from these two Poaceae hosts. Our alternative hypothesis was that specialized pathogen populations would exist on each host population but populations would not be genetically isolated or would be only partially isolated. A secondary goal was to determine the reproductive system on both hosts. Based on our earlier findings in Brazil (15), China (7,8), India (38), and the United States (Louisiana [6] and Texas [59]), we tested the null hypothesis that Latin American populations from rice and maize would be mainly randommating, with local dispersal of a few asexual clones. We also considered two alternate hypotheses: rice- and maize-infecting populations from Latin America are mainly clonal or rice- and maize-infecting populations from Latin America have different degrees of clonality.

\section{MATERIALS AND METHODS}

Population sampling and data collection. Three geographically paired rice- and maize-infecting populations of $R$. solani AG-1 IA from Venezuela were sampled from naturally infected fields in Portuguesa State. In total, 211 isolates (139 from rice cv. Fedearroz 50 and 72 isolates from maize cv. Dekalb 777) were obtained in 2005 from three different counties-Turén, Santa Rosalía, and Esteller-representing the most important rice and maize production areas in Venezuela (Fig. 1). The sympatric rice $(\mathrm{VNZ} \mathrm{R})$ and maize (VNZ M) field populations were $\approx 5 \mathrm{~km}$ apart, while the three locations were separated by 10 to $35 \mathrm{~km}$. Rice was cropped under paddy irrigation while hybrid maize was cropped under upland conditions. All fields were sampled using the same collection strategy to allow a meaningful comparison of clonal fractions among distinct field populations. Plants showing symptoms characteristic of rice SB or maize BLSB were collected using transect sampling from six fields (three from rice and three from maize). In each field, infected plants from five to six disease foci (at least $10 \mathrm{~m}$ apart) were collected along each transect from a total of six to eight transects per field (totaling 30 to 48 foci per field). Isolates were obtained as formerly described $(6,34)$. One isolate was kept from each focus to include in the analysis. Sclerotia produced by each isolate were transferred into $1.8-\mathrm{ml}$ cryo-tubes (Nunc CryoLine System, Denmark) containing sterilized silica gel (Fluka Chemie GmbH, Germany) for longterm storage at $4^{\circ} \mathrm{C}$. The $\mathrm{AG}$ of each isolate was determined by sequencing the internal transcribed spacer $5.8 \mathrm{~S}$ region and comparing with sequences from AG-1 IA isolates (23).

Two rice-infecting populations of $R$. solani AG-1 IA were included as allopatric populations: one from Colombia $(n=103$ isolates, sampled in Meta State from upland rice cv. Tailandia 3) and another from Panama ( $n=61$ isolates, sampled from Chiriquí State from an irrigated field of paddy rice Fedearroz 50). Collections from both fields were made using the same transect sampling described earlier. The population from Colombia (COL $\mathrm{R})$ was $\pm 850 \mathrm{~km}$ distant from the rice- and maize-infecting populations from Venezuela while the population from Panama (PAN R) was $\pm 1,500 \mathrm{~km}$ distant. The field populations from Colombia and Panama were separated by $\pm 900 \mathrm{~km}$.

Fungal mycelia production and genomic DNA extraction were done as described earlier for $R$. solani AG-1 IA (38). Ten polymorphic co-dominant microsatellite simple sequence repeat (SSR) loci were used to genotype the isolates using fluorescentlabeled primers as reported by Zala et al. (72). Two control isolates (Tc05US_KatC6 and Tc05VNZ_A1A1) were included in 
every run of 94 samples. An additional test for reproducibility of the microsatellite allele assignments was made by comparing sizes of each allele at every locus for the maize population from Santa Rosalía, which was independently genotyped twice. The data from this second independent genotyping were used to describe the microsatellite genotyping system (72). The statistical binning of alleles into fragment size categories consistent with the respective unit increment described by Zala et al. (72) was implemented using the program Flexibin (3). Based on the observed number of repeats found for the microsatellite loci in this and three other studies $(6,7,15)$, we assumed a stepwise mutation model (SMM) in all of the analyses. We also performed the neutrality test proposed by Vitalis et al. $(68,69)$ on the microsatellite data and found no evidence for selection at any of the ten loci.

Data analyses. In all analyses, we assumed that $R$. solani AG-1 IA is a functional diploid (i.e., it is a dikaryon) (1). All of our data were consistent with this assumption.

Genotypic diversity. A multilocus microsatellite genotype (MLMG) for each strain was determined using the program GENOTYPE (Institute for Biodiversity and Ecosystem Dynamics, Universiteit van Amsterdam, Amsterdam) (43). Isolates with the same MLMG were treated as clones. Several indices of clonal diversity were calculated, including: (i) the number of genotypes per population; (ii) site-specific genotypes; (iii) the clonal fraction (or the proportion of fungal isolates originating from asexual reproduction), calculated as $1-$ [(number of different genotypes)/ (total number of isolates)]; (iv) both the Stoddart and Taylor's genotypic diversity, $G_{o}=1 / \Sigma p_{i}^{2}$ where $p_{i}$ is the frequency of the $i$ th genotype (64), and its evenness $\left(G_{o}\right.$ scaled by the maximum number of expected genotypes) an indicator for how evenly the genotypes are distributed over the population. These measures were determined using GENODIVE (v.2.0b7; Institute for Biodiversity and Ecosystem Dynamics, Universiteit van Amsterdam, Amsterdam) (43). To test whether pairs of populations differed in their clonal diversity, we used a bootstrapping approach (resampling with replacement), where the individuals were resampled from the populations and the diversity indices were compared after every replicate, using 1,000 permutations, with subsampling to match the size of the smallest population (25).

Gene diversity and differentiation among distinct hostspecific populations. For these analyses, we used a clone-corrected data set in which only a single individual for each MLMG was included per population. Nei's unbiased gene diversity was estimated as $n /(n-1) \times\left(1-\Sigma_{i} p_{i}^{2}\right)$, where $p$ is the observed frequency of the $i$ th allele (48). Allelic richness was estimated as the mean number of alleles per locus (17) using rarefaction (29) as described by Petit et al. (55). To test whether groups of samples differed for gene diversity and allelic richness, we used FSTAT v. 2.9.3.2 (24). $P$ values for the pairwise comparisons were obtained after 1,000 permutations.

The degree of population subdivision and the distribution of gene diversity among sympatric host and allopatric regional populations of $R$. solani AG-1 IA was evaluated using contrasts based on hierarchical analyses of molecular variance (AMOVA) $(18,70)$. By defining groups of populations, two series of contrasts were tested: (i) among sympatric rice- and maize-infecting populations from Venezuela: rice versus maize, populations within the rice-infecting group, and populations within the maize-infecting group; and (ii) among allopatric country populations from Latin America: Colombia versus Venezuela rice or maize, Panama versus Venezuela rice or maize, and Colombia versus Panama. As the distance measure, we used the sum of squared size differences $\left(R_{S T}\right)$ between two haplotypes, according to Slatkin (61). A hierarchical analysis of variance was conducted to partition the covariance components into: among groups of host or regional populations, among populations within groups, and within populations. Significance of the fixation indices $\left(\Phi_{S T}\right.$ statistics, analogous to $F_{S T}$ ) was tested using 1,023 permutations by a nonparametric approach. This analysis was conducted using the program ARLEQUIN (v.3.11; Zoological Institute, Department of Biology, University of Bern, Switzerland) (18).

We also determined whether population subdivision followed the isolation-by-distance (IBD) model proposed by Mantel (40). Mantel's test was carried out using GENODIVE v.2.0b7 (43), assuming a linear relationship between pairwise values of $\Phi_{\mathrm{ST}} /$ $\left(1-\Phi_{\mathrm{ST}}\right)$ and the natural logarithm of geographical distances $(\mathrm{km})$ between all rice-infecting population pairs $(60)$. The significance of the relationship was assessed with 1,000 permutations using GENODIVE v.2.0b7 (43).

Hardy-Weinberg and gametic equilibrium tests. To assess the relative contributions of asexual and sexual reproduction in different hosts and regional populations, we first tested for HardyWeinberg equilibrium (HWE) using a measure analogous to the Fisher exact test (26). The $P$ values were obtained using a Markov chain Monte Carlo (MCMC) approach, generating an exact probability distribution not biased by rare alleles (58). This test was implemented in ARLEQUIN v.3.11 (18). Inbreeding, a possible cause of deviation from HWE, was quantified based on measures of $F_{I S}(71)$ to test for a significant deficit or excess of heterozygotes (when compared with HWE expectations), calculated with ARLEQUIN v.3.11 (18). Significance was assessed with 1,023 permutations.
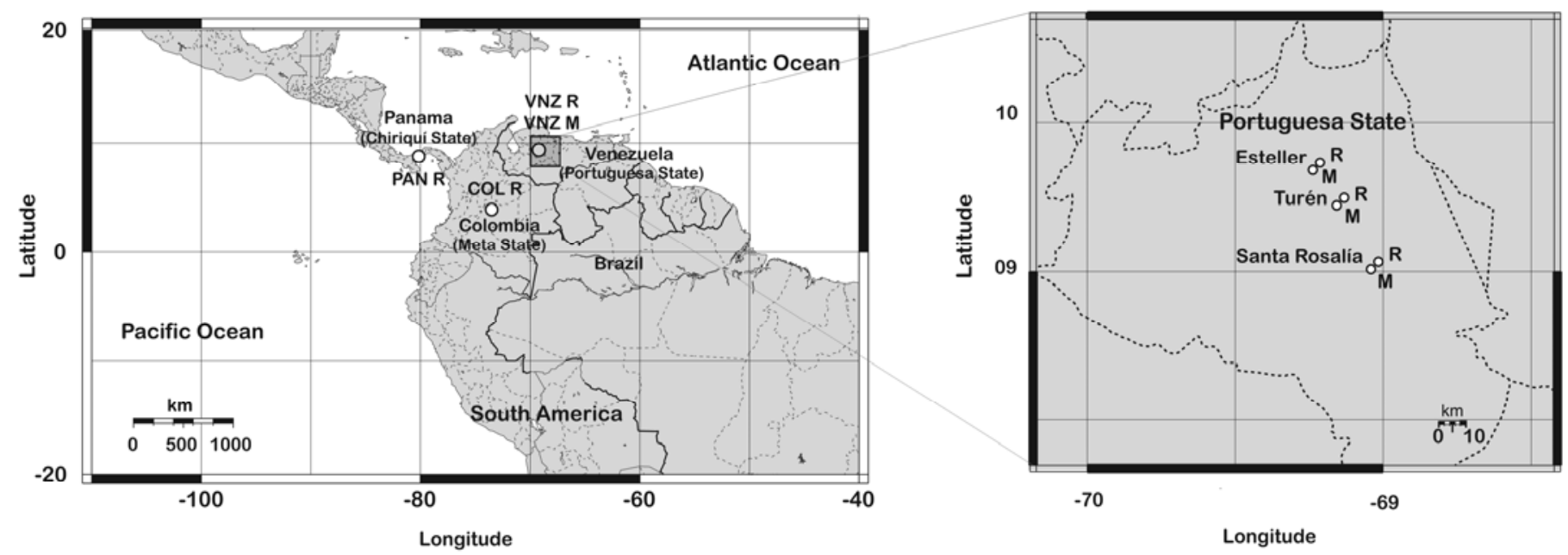

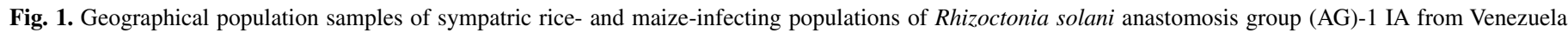
and allopatric rice-infecting populations from Latin America. The latitude (N-S) and longitude values (W-E) are indicated in the maps. 
Gametic equilibrium (GE) was tested using a multilocus association test (10). The hypothesis that genotypes at one locus are independent from genotypes at another locus was tested using Fisher's exact test and an MCMC algorithm (with 1,000 batches and 1,000 iterations/batch). This test was implemented using the program GENEPOP (v.3.4; Institut des Sciences del'Evolution, Université Montpellier 2, Montpellier, France) (58). A Bonferroni correction was applied to this analysis to avoid false rejections of the null hypothesis due to the large number of comparisons performed (9). Two loci were considered in GE when their associated $P$ value was $>0.05 / n$, where $n$ is the number of comparisons. We also measured the index of association $\left(I_{A}\right)$ for each population using the program MULTILOCUS (v.1.3; Department of Biology, Imperial College, Silwood Park, U.K.) (2) based on 1,000 randomizations. We tested the hypothesis of complete panmixia by comparing the observed dataset to datasets in which an infinite amount of sexual recombination has been imposed on the data by randomly shuffling the alleles amongst individuals independently for each locus. An $I_{A}$ significantly different from zero means disequilibrium. The absence of gametic disequilibrium between loci is considered evidence for the occurrence of recombination. For these analyses, we used a clone-corrected data set.

Test for admixture or hidden population structure. Population admixture could be one of the causes of observed departures from HWE and GE. To determine whether any individuals in a sample were immigrants with respect to their reference geographical population, we used an assignment test performed with a Bayesian statistical model (57) implemented by STRUCTURE 2.2 (57). This program calculates the membership coefficients ( $\hat{Q}$ ) of every MLMG to each of the populations. The MLMGs are assigned a priori to their reference population. By including this prior information, MLMGs in the sample are assigned probabilistically to their reference population or jointly to two or more populations, if their genotypes are consistent with admixture. We performed 10 runs of MCMC simulations, with an initial burn-in of 10,000 followed by 100,000 iterations. Parameters were set using eight clusters $(K=8)$, an admixture model, and $F_{S T}$ values previously calculated with ARLEQUIN 3.11 (18).

Test for population size fluctuation and historical migration. Population size fluctuation was tested using an MCMC method implemented in LAMARC (v.2.1.3; Department of Genome Sciences, University of Washington, Seattle) $(36,37)$. Estimates of population growth among populations were obtained using five independent replicates of 10 initial chains and five long final chains, and a static heating scheme with four temperatures $(1.0,1.3,2.6$, and 3.9). The 10 initial short chains were performed with 2,000 samples and a sampling interval of 20 (40,000 steps), using a burn-in of 1,000 samples for each chain and 2,000 genealogies recorded per chain. The five final long chains were carried out with 20,000 samples and a sampling interval of 20 (400,000 steps) and burn-in of 10,000, and 20,000 trees recorded for each chain. The credibility or confidence interval for the growth rate was calculated using the percentile approach. LAMARC reports a probability density curve containing the highest point as the estimate for that parameter and credibility intervals (CIs) at distinct percentiles. The combination of the 0.025 percentile and the 0.975 percentile gives the $95 \%$ CIs. The ancestral $N_{e}$ at time $(t)$ ago was calculated using the following equation of population growth: $\theta_{t}=\theta_{\text {now }} e^{-\mathrm{gt}}$, where $\theta$ is $4 N_{e} \mu, t$ is the time in mutational units, and $g$ is the exponential growth parameter.

Historical migration between populations was estimated with MIGRATE (v.3.0.3; Department of Biological Science, Florida State University, Tallahassee) (5). MIGRATE is based on coalescent theory and uses a maximum likelihood approach to estimate effective population sizes (theta $=\theta$, also called population diversity) and a migration matrix. It allows for estimation of asymmetrical migration $(M)$ between population pairs. The program assumes that populations have a constant population size through time, that they follow a Wright-Fisher model of equilibrium between migration and drift, and that the mutation rate, $\mu$, is constant $(4,5)$. Estimates of gene flow among populations were obtained using five independent replicates of 10 initial short chains and five final long chains, and a static heating scheme with four temperatures $(1.0,1.3,2.6$, and 3.9). The data type chosen was microsatellite data with Brownian motion, assuming the stepwise mutation model. The initial chains were performed with 1,000 samples and a sampling interval of 20 (20,000 steps), with 1,000 trees recorded per short sample. The five final chains were carried out with 5,000 samples and a sampling interval of 20 (200,000 steps), a burn-in of 10,000, and 10,000 trees recorded per long chain. The confidence interval for $\theta$ and migration parameter $M$ was calculated using a percentile approach (5). Likelihood ratio tests (LRTs) were used to test the hypothesis of asymmetric $M$. The LRT implemented in MIGRATE v.3.0.3 compares the maximum likelihood of the migration rate estimates with the likelihood when $M$ is restricted to the same value as the mean of the estimates from a population pair. If $P \leq 0.05$ for a particular LRT, we would reject the null-hypothesis and accept the alternative that the values are not equal (i.e., asymmetrical).

IM estimation of splitting parameter $(s)$ and divergence time $(t)$. We used the IM program (Evolutionary Genetics Lab, Department of Genetics, Rutgers University; revision from 5 March 2007) to estimate $s$ and $t$. The IM program estimates Bayesian posterior likelihood distributions of $\theta$ of the ancestral founding population and of the two present-day populations; $t$, the population divergence time; $m$, gene flow between populations (the number of migrants exchanged per generation between the two populations); $s$, the splitting parameter (the fraction of the ancestral population that founded the maize-infecting population of $R$. solani AG-1 IA, where $0<s<1$ ); and $\mu$ (mutation rate) given (i) a demographic model, (ii) the entire set of data (the 10 microsatellite loci) and the likelihood of their possible underlying genealogies calculated using a MCMC approach, and (iii) a mutational model. Based on previous MIGRATE and LAMARC estimates of the demographic parameters $\theta$ and population growth $(g)$, we assumed constant population size since divergence and equal population sizes for both maize-infecting $\left(\theta_{1}\right)$ and riceinfecting $\left(\theta_{2}\right)$ populations of the pathogen (i.e., $\left.\theta_{\mathrm{A}}=\theta_{1}=\theta_{2}\right)$. We used a stepwise mutation model, common for microsatellite loci, which is useful for analyses of recent cases of population splitting (28).

Bayesian posterior likelihood distributions for $\theta, m(m=m \mu)$, and $t(t=t \mu)$ were calculated using $\approx 1,000,000$ simulations and a burn-in time of 50,000. We used Metropolis Coupling based on five chains and a two-step increment model as described by Nielsen and Wakeley (49) and Hey and Nielsen in the IM documentation from 2007 (Evolutionary Genetics Lab, Department of Genetics, Rutgers University). Scalar for maximum $\theta$ values was 42.75 , and was set at 5 as maximum migration rates $(m)$ and 20 as maximum divergence time $(t)$. Inheritance scalar was set at 1 for autosomal loci. We repeated independently every run five times with different random number seeds. Marginal histograms were compared between all independent runs for all parameters. Lower and upper bounds of the estimated $95 \%$ confidence intervals were calculated for each parameter.

The IM analysis uses the estimate $\mu$ (mutation rate per locus per year of each locus) to infer $t$ (time since divergence of populations). To convert the estimates of $t$ into real time, an overall mutation rate per locus per year is needed. We applied to locus TC02 (for which IM estimated a mutation rate scalar $=1.0$ ) the mean mutation rate estimate inferred by Dettman and Taylor (16) for microsatellite loci in Neurospora spp. $\left(\mu=1.39 \times 10^{-05}\right.$ mutation per site per year). The mutation rates of the other nine 
microsatellite loci were then estimated using their corresponding mutation rate scalars estimated by IM. We assumed four fungal generations per year $(n=4)$ because a complete infection cycle, from basidiospore germination and infection to secondary basidiospore dispersal, would take 2 weeks and would likely be repeated four times during a growing season $(27,46)$. Thus, the mean mutation rate across the 10 microsatellite loci was estimated as $7.6 \times 10^{-05}$ substitutions per site per year (ranging per locus from $5.3 \times 10^{-05}$ to $15.9 \times 10^{-05}$ substitutions per site per year). The coalescence time $t$ in years was calculated as: $t=\mathrm{t} / \mu \times n$ (where $t$ is the IM time estimate and $\mu$ is the overall mutation rate).

Cross-pathogenicity test. In all, 10 rice- and 9 maize-infecting isolates of $R$. solani AG-1 IA were selected based on having unique and representative multilocus SSR genotypes. A comparison of the two sets of host-associated multilocus SSR genotypes yielded a pairwise $\Phi_{\mathrm{ST}}$ maize versus rice $=0.099, P \leq 0.01$, consistent with significant genetic divergence between the two groups of isolates. The fungal inoculum was produced in plastic bags containing $100 \mathrm{~g}$ of sterilized polished rice grains mixed with $30 \mathrm{ml}$ of water. Ten 9-mm-diameter potato dextrose agar disks colonized with $R$. solani AG-1 IA isolates were transferred to each bag and incubated for 8 days at room temperature. Plants were inoculated by adding $1 \mathrm{~g}$ of inoculum to the stem base of two healthy 30-day-old maize and rice plants per pot, at soil level, as described by Pineda (56). Sterilized rice grains were used to inoculate the checks. The plants were incubated for 8 days at $30^{\circ} \mathrm{C}$ and $100 \%$ humidity maintained by microchambers built with 2-liter plastic bottles (32). The choice of cultivars (maize cv. D-3273 and rice cv. Lemont) was based on information about the susceptibility of these rice and maize cultivars. Up until now, there are no reported sources of major resistance among the cultivars or lines utilized in breeding programs $(32,56)$. The disease was scored using an index based on the ratio between the length of typical rice SB or maize BLSB lesions and plant height $(32,56)$. The experiments were arranged in a completely randomized design, with three and four replicated pots for maize and rice, respectively. The entire experiment was repeated twice. Analysis of variance was performed using the SAS statistics software package (version 9.1 of the SAS System for Windows; SAS Insti- tute Inc., Cary, NC). Using PROC MIXED and CONTRAST statements, we calculated two contrasts of interest for each experiment: (i) inoculated versus noninoculated treatments and (ii) maize-derived versus rice-derived isolates.

\section{RESULTS}

Microsatellite gene and genotypic diversity. The allele frequency distributions per locus and per population are presented in supplemental material (e-Xtra). Between 3 and 11 alleles were found per locus (e-Xtra). Across all 10 loci, the total number of private alleles was 19: 6 and 4 were detected on the rice- and maize-infecting population from Venezuela, respectively; 4 in the population from Colombia; and 5 from Panama.

All together, 184 MLMGs were detected. No MLMGs were shared among the regional populations. Higher clonal fractions (of 0.62 to 0.83 ) and significantly lower genotypic diversities $\left(G_{o}\right.$ of 3.6 to 8.8) were observed for the populations from Panama and Colombia when compared with the rice- and maize-infecting populations from Venezuela.

Within Portuguesa State, Venezuela, there were significant differences in clonal fractions among sympatric populations from rice and maize (Table 1). In total, 82 MLMGs were detected in the sympatric rice-infecting populations from Venezuela. Within this group, every isolate sampled from Santa Rosalía had a different genotype. In contrast, higher clonal fractions (of 0.22 to 0.53 ) were observed in the rice-infecting populations from Turén and Esteller. Three of the MLMGs observed on rice were found in more than one rice field but none of the rice-infecting MLMGs were found in populations originating from maize. Within the maize-infecting group, all isolates from Esteller had different MLMGs. Clonal fractions were 0.13 to 0.25 in Santa Rosalía and Turén populations. Of the 61 MLMGs, 1 was shared among maize fields. When populations were combined into host-specific groups, the genotypic diversity was significantly higher $(P=0.05)$ for the maize-infecting population $\left(G_{o}=48.0\right)$, which also had genotypes occurring at more even frequencies (evenness $=0.79$ ). Santa Rosalía was the population with the highest genotypic diversity for both host-specific populations $\left(G_{o}=27.0\right.$ and 22.3 for the rice- and maize-infecting populations, respectively).

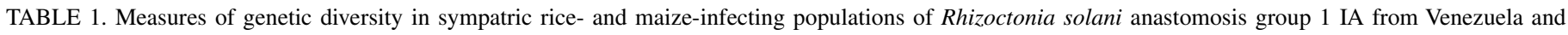
allopatric rice-infecting populations from Latin Americas

\begin{tabular}{|c|c|c|c|c|c|c|c|c|}
\hline $\begin{array}{l}\text { Country, host populations, } \\
\text { location }\end{array}$ & $\begin{array}{l}\text { Sample size } \\
(n)^{\mathrm{t}}\end{array}$ & $\begin{array}{c}\text { No. of } \\
\text { genotypes }\end{array}$ & $\begin{array}{l}\text { Site-specific } \\
\text { genotypes }^{\mathrm{u}}\end{array}$ & $\begin{array}{l}\text { Clonal } \\
\text { fraction }\end{array}$ & $G_{o}^{\mathrm{v}}$ & Evenness $^{\mathrm{w}}$ & $\mathrm{H}_{\mathrm{e}}^{\mathrm{x}, \mathrm{y}}$ & $\begin{array}{l}\text { Allelic } \\
\text { richness } \\
\text { y,z }\end{array}$ \\
\hline \multicolumn{9}{|l|}{ Venezuela, rice-infecting } \\
\hline Populations combined & 139 & 82 & $82(0)$ & 0.41 & $20.44 \mathrm{~B}$ & $0.25 \mathrm{C}$ & $0.50 \mathrm{~A}$ & $3.84 \mathrm{~A}$ \\
\hline Turén & 18 & 14 & $13(1)$ & 0.22 & $8.53 \mathrm{e}$ & $0.61 \mathrm{c}$ & $0.56 \mathrm{a}$ & $3.63 \mathrm{a}$ \\
\hline Santa Rosalía & 27 & 27 & $25(2)$ & 0.00 & $27.00 \mathrm{a}$ & $1.00 \mathrm{a}$ & $0.55 \mathrm{ab}$ & $3.44 \mathrm{ab}$ \\
\hline Esteller & 94 & 44 & $41(3)$ & 0.53 & $10.16 \mathrm{e}$ & $0.23 \mathrm{~d}$ & $0.56 \mathrm{a}$ & $3.60 \mathrm{a}$ \\
\hline \multicolumn{9}{|l|}{ Venezuela, maize-infecting } \\
\hline Populations combined & 72 & 61 & $61(0)$ & 0.15 & $48.00 \mathrm{~A}$ & $0.79 \mathrm{~A}$ & $0.47 \mathrm{~B}$ & $3.61 \mathrm{~A}$ \\
\hline Turén & 24 & 18 & $17(1)$ & 0.25 & $13.71 \mathrm{~d}$ & $0.76 \mathrm{bc}$ & $0.49 \mathrm{bc}$ & $3.26 \mathrm{bc}$ \\
\hline Santa Rosalía & 32 & 28 & $27(1)$ & 0.13 & $22.26 \mathrm{~b}$ & $0.80 \mathrm{~b}$ & $0.53 \mathrm{ab}$ & $3.48 \mathrm{ab}$ \\
\hline Esteller & 16 & 16 & $16(0)$ & 0.00 & $16.00 \mathrm{c}$ & $1.00 \mathrm{a}$ & $0.46 \mathrm{c}$ & $3.18 \mathrm{c}$ \\
\hline \multicolumn{9}{|l|}{ Colombia, rice-infecting } \\
\hline Meta & 103 & 18 & $18(0)$ & 0.83 & $3.57 \mathrm{D}$ & $0.19 \mathrm{C}$ & $0.51 \mathrm{~A}$ & $3.06 \mathrm{~B}$ \\
\hline \multicolumn{9}{|l|}{ Panama, rice-infecting } \\
\hline Chiriquí & 61 & 23 & $23(0)$ & 0.62 & $8.80 \mathrm{C}$ & $0.38 \mathrm{~B}$ & $0.51 \mathrm{~A}$ & $3.62 \mathrm{~A}$ \\
\hline Total & 375 & 184 & $\ldots$ & $\ldots$ & $\ldots$ & $\ldots$ & $\ldots$ & $\ldots$ \\
\hline
\end{tabular}

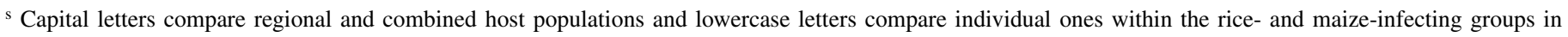

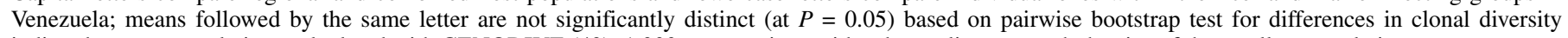
indices between populations calculated with GENODIVE (43); 1,000 permutations with subsampling to match the size of the smallest population.

t Sample size of each population.

u Number of genotypes shared with other populations are shown in parentheses; light shading indicates the main groups of host and country populations.

v Stoddart and Taylor's genotypic diversity $(63,64)$.

${ }^{\mathrm{w}} G_{o}$ scaled by the maximum number of expected genotypes; an evenness value $=1.0$ indicates that all genotypes have equal frequencies.

x Nei's unbiased gene diversity (48), also known as expected heterozygosity, averaged over all loci and corrected for sample size.

y To test whether pairwise samples differed for Nei's unbiased gene diversity and allelic richness, we used FSTAT v.2.9.3.2 (24), based on 1,000 permutations.

${ }^{\mathrm{z}}$ Calculated according to El Mousadik and Petit (17). 
Among the 143 MLGTs from sympatric rice and maize from Venezuela, 142 were heterozygous for at least one locus. All the MLMGs were heterozygous for at least one locus in Colombia $(n=18)$ and Panama $(n=23)$. The mean expected heterozygosity $\left(\mathrm{H}_{\mathrm{E}}=\right.$ Nei's unbiased gene diversity) was significantly higher in all the rice-infecting populations from Latin America $\left(\mathrm{H}_{\mathrm{E}}\right.$ rice-infecting $=0.50-0.51$ and $\left.\mathrm{H}_{\mathrm{E} \text { maize-infecting }}=0.47\right)($ Table 1$)$. The mean allelic richness values were not significantly different $(P<0.05)$ between the sympatric rice- and maize-infecting populations from Venezuela and also between these two populations and the population from Panama. The Colombian population had the lowest allelic richness $(=3.06)$. In Venezuela, the lowest allelic richness $(=3.18)$ was observed in the maize-infecting population from Esteller.

Differentiation among host populations. AMOVA contrasts between sympatric distinct host populations from Venezuela indicated that the rice-infecting populations were significantly differentiated from the maize-infecting populations $\left(\Phi_{S T} \approx 0.17\right.$, $P \leq 0.001$ ) (Table 2). Pairwise comparisons between sympatric rice- and maize-infecting populations indicated that they were subdivided in all three counties (pairwise $\Phi_{S T}$ of 0.16 to $0.22, P \leq$ 0.001). The within-group comparisons also indicated subdivision among the rice-infecting $\left(\Phi_{S T} \approx 0.03, P \leq 0.02\right)$ and among the maize-infecting populations $\left(\Phi_{S T} \approx 0.06, P \leq 0.001\right)$ from the three locations (Table 2). However, these within-group $\Phi_{S T}$ values were significantly smaller than the ones observed for the between-group comparisons ( $t$ values ranged from $3.16[P=0.034]$ to $5.67[P=0.005])$. The two allopatric rice-infecting populations from Colombia and Panama were significantly subdivided from both the rice-infecting $\left(\Phi_{S T}=0.15\right.$ to $\left.0.16, P \leq 0.001\right)$ and the maize-infecting $\left(\Phi_{S T}=0.19\right.$ to $\left.0.34, P \leq 0.001\right)$ populations from Venezuela.

The significant correlation between genetic distance $\left[\Phi_{S T} /(1-\right.$ $\left.\Phi_{S T}\right]$ and geographical distance among the rice-infecting populations $\left(R^{2}=0.59 ; P<0.05\right)$ provided evidence that gene flow decreases as the distance between populations increases.

HWE and GE tests. The sympatric rice-infecting populations from Venezuela showed significant deviations from HWE for many loci, with HWE rejected 12 times out of 28 total tests in the individual populations. When all three rice populations were combined, only 3 of 10 loci were in HWE. In the sympatric maize populations from Venezuela, either individually or combined, most of the loci were in HWE (8 to 9 of 10) (Table 3). In Venezuela, only the rice-infecting population from Esteller had a

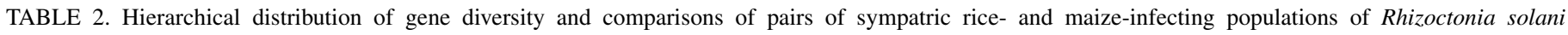
anastomosis group 1 IA from Venezuela and allopatric rice-infecting populations from Latin America ${ }^{\mathrm{z}}$

\begin{tabular}{|c|c|c|}
\hline Contrasts & $\Phi_{\mathrm{ST}}$ & $P$ value \\
\hline \multicolumn{3}{|l|}{ Sympatric rice- and maize-infecting populations from Venezuela } \\
\hline Rice-infecting versus maize-infecting & 0.173 & 0.001 \\
\hline Populations within rice-infecting group & 0.030 & 0.020 \\
\hline Populations within maize-infecting group & 0.056 & 0.001 \\
\hline \multicolumn{3}{|l|}{ Allopatric populations from Latin America } \\
\hline Colombia rice-infecting versus Venezuela rice-infecting & 0.164 & 0.001 \\
\hline Colombia rice-infecting versus Venezuela maize-infecting & 0.345 & 0.001 \\
\hline Panama rice-infecting versus Venezuela rice-infecting & 0.150 & 0.001 \\
\hline Panama rice-infecting versus Venezuela maize-infecting & 0.188 & 0.001 \\
\hline Colombia rice-infecting versus Panama rice-infecting & 0.187 & 0.001 \\
\hline
\end{tabular}

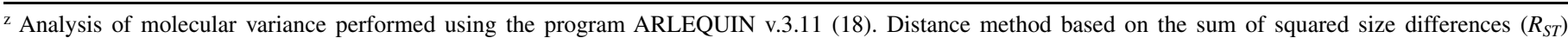
between two haplotypes, for microsatellite data (61); number of permutations $=1,023$. Light shading indicates the groups of contrasts between populations.

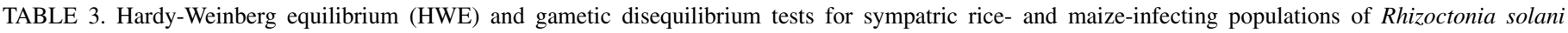
anastomosis group 1 IA from Venezuela and allopatric rice-infecting populations from Latin America

\begin{tabular}{|c|c|c|c|c|c|c|c|c|c|}
\hline $\begin{array}{l}\text { Country and host } \\
\text { populations }\end{array}$ & Location & $\begin{array}{c}\text { Clone } \\
\text { corrected }(n)\end{array}$ & $\begin{array}{l}\text { No. of } \\
\text { loci } \\
\text { under } \\
\text { HWE }^{u}\end{array}$ & $F_{I S}{ }^{\mathrm{v}}$ & $P$ value ${ }^{v}$ & $I_{A}{ }^{\mathrm{w}}$ & $P$ value ${ }^{\mathrm{x}}$ & $\begin{array}{l}\text { Locus pairs at } \\
\text { significant } \\
\text { disequilibrium }\end{array}$ & Percent \\
\hline \multirow[t]{6}{*}{ Venezuela, rice-infecting } & Populations combined & 82 & $3 / 10$ & 0.07 & 0.13 & 1.042 & $<0.01$ & $21 / 45$ & 46.7 \\
\hline & Turén & 14 & $7 / 9 *$ & -0.13 & 0.77 & 1.390 & $<0.01$ & $1 / 36$ & 2.8 \\
\hline & Santa Rosalía & 27 & $5 / 9 *$ & -0.10 & 0.74 & 1.621 & $<0.01$ & $14 / 36$ & 38.9 \\
\hline & Santa Rosalía with no admixture ${ }^{\mathrm{z}}$ & 20 & $6 / 9 *$ & -0.10 & 0.31 & 1.388 & $<0.01$ & $9 / 36$ & 25.0 \\
\hline & Esteller & 44 & $4 / 10$ & 0.27 & 0.00 & 1.105 & $<0.01$ & $16 / 45$ & 35.6 \\
\hline & Esteller with no admixture ${ }^{z}$ & 35 & $6 / 9 *$ & 0.27 & 0.00 & 0.833 & $<0.01$ & $13 / 36$ & 36.1 \\
\hline \multirow[t]{4}{*}{ Venezuela, maize-infecting } & Populations combined & 61 & $8 / 10$ & -0.05 & 0.07 & 0.261 & 0.06 & $4 / 45$ & 8.9 \\
\hline & Turén & 18 & $9 / 10$ & 0.04 & 0.34 & 0.422 & 0.08 & $3 / 45$ & 6.7 \\
\hline & Santa Rosalía & 28 & $8 / 10$ & -0.19 & 0.96 & 0.250 & 0.20 & $1 / 45$ & 2.2 \\
\hline & Esteller & 16 & $9 / 9 *$ & -0.03 & 0.57 & 0.471 & 0.01 & $0 / 35$ & 0.0 \\
\hline Colombia, rice-infecting & Meta & 18 & $4 / 9 *$ & -0.38 & 0.99 & 2.17 & $<0.001$ & $12 / 36$ & 33.3 \\
\hline Panama, rice-infecting & Chiriquí & 23 & $7 / 10$ & 0.43 & 0.00 & 0.62 & $<0.001$ & $5 / 45$ & 11.1 \\
\hline
\end{tabular}

" HWE test performed according to an exact test analogous to Fisher's, using a Markov chain with length of 100,000 (26); *one monomorphic locus.

v Population-specific $F_{I S}$ indices and $P$ values calculated based on 1,023 permutations using ARLEQUIN 3.11 (18).

${ }^{\mathrm{w}} I_{A}$ is an index of multilocus gametic disequilibrium (for the random association of alleles among distinct locus pairs) (2).

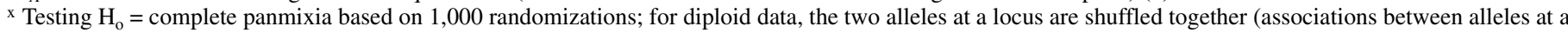
locus are maintained in the randomized data sets); thus, the test is purely for associations between loci (2).

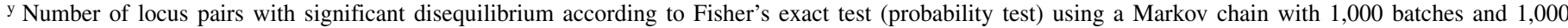
iterations/batch, implemented by GENEPOP (58), after Bonferroni correction to avoid false rejections of the null hypothesis due to the large number of comparisons performed (9).

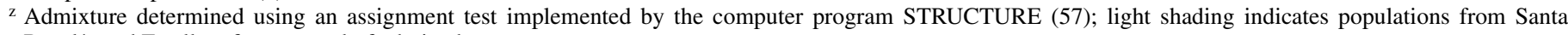
Rosalía and Esteller after removal of admixed genotypes. 
significant $F_{I S}(0.27 ; P \leq 0.01)$. Although the allopatric riceinfecting population from Panama had most loci in HWE (7 of 10 ), only 4 of 9 loci were in HWE in the population from Colombia. A significant $F_{I S}(0.43, P \leq 0.01)$ was detected for the population from Panama.

Using the index of association test $\left(I_{A}\right)$, we rejected the null hypothesis of random associations among loci for all rice populations from Venezuela, individually and combined. In contrast, GE was not rejected for the maize-infecting populations from Turén and Santa Rosalía. No deviations from GE were detected in the pooled maize populations. We also tested for gametic disequilibrium in each population by using pairwise tests among loci based on MCMC. After Bonferroni correction, we used the percentage of significant disequilibrium values as a measure of overall disequilibrium (Table 3 ). The proportion of loci with significant pairwise deviations from equilibrium was 3 to $39 \%$ within the sympatric rice-infecting groups and 0 to $7 \%$ in the sympatric maize-infecting group from Venezuela. GE was rejected for both allopatric rice-infecting populations from Panama and Colombia (significant $I_{A}$ and proportion of locuspairs in significant disequilibrium of 11 to $33 \%$ ).

Test for admixture or hidden population structure. Overall, $15 \%$ admixture was detected in the sympatric samples from Venezuela, corresponding to 22 genotypes that could be assigned to more than one cluster or to a cluster distinct from the one corresponding to its reference population (e-Xtra). However, the amount of admixture varied considerably among host populations. No admixed genotypes were found in the maize-infecting population from Esteller and only 3 to $5 \%$ in Santa Rosalía and Turén. The rice-infecting populations had the most admixture, with proportions of admixed genotypes of 21 to $35 \%$. The graphical representation of admixture is shown in the supplemental material (e-Xtra). No admixture was detected between the populations from Venezuela and the allopatric population from Colombia. The population from Panama had one admixed genotype with the rice-infecting population from Esteller.

Test for historical migration and population size fluctuation. The population parameter $\Theta$ was used as a relative measure of effective population size. The sympatric rice- and maize-infecting populations from Venezuela and the allopatric rice-infecting populations from Colombia and Panama had similar population size estimates $(\Theta=0.84$ to 0.98 ) (Fig. 2; e-Xtra). There was no evidence for either population expansion or contraction. All the populations showed either slightly positive (COL R) or slightly negative growth rate estimates (VNZ_M, VNZ R, and PAN R). However, these values were not significantly different from zero (Fig. 2). Estimates of directional gene flow indicated symmetrical historical migration between the sympatric rice- and maize-infecting populations from Venezuela (migration rate $4 N m_{\mathrm{VNZ} \mathrm{R} \rightarrow \mathrm{VNZ} \mathrm{M}}=1.92\left[\mathrm{CI}_{95 \%}=1.57\right.$ to 2.31$]$ and $4 N m_{\mathrm{VNZ} \mathrm{M} \rightarrow \mathrm{VNZ} \mathrm{R}}$ $=2.55\left[\mathrm{CI}_{95 \%}=2.08\right.$ to 3.03]) (Fig. 2; e-Xtra). In contrast, the allopatric rice-infecting populations from Colombia and Panama exchanged significantly fewer migrants with the maize-infecting population from Venezuela $\left(4 N m_{\mathrm{COL} \mathrm{R} \rightarrow \mathrm{VNZ} \mathrm{M}}=0.49\left[\mathrm{CI}_{95 \%}=0.34\right.\right.$ to 0.67$]$ and $4 N m_{\mathrm{PAN} \mathrm{R} \rightarrow \mathrm{VNZ} \mathrm{M}}=0.81\left[\mathrm{CI}_{95 \%}=0.60\right.$ to 1.06$\left.]\right)$. The two allopatric populations from Colombia and Panama also contributed significantly fewer migrants $(0.72$ to 0.60 migrants/generation) to the rice-infecting population from Venezuela. The exchange of immigrants between Colombia and Panama rice-infecting populations was significantly asymmetrical $\left(4 N m_{\mathrm{COL} \mathrm{R} \rightarrow \mathrm{PAN} R}=\right.$ $1.07\left[\mathrm{CI}_{95 \%}=0.81\right.$ to 1.38$]$ and $4 N m_{\mathrm{PAN} \mathrm{R} \rightarrow \mathrm{COL} \mathrm{R}}=0.59\left[\mathrm{CI}_{95 \%}=\right.$ 0.39 to 0.80$])$.

IM estimates of splitting parameter $(s)$ and divergence time $(t)$. The IM estimates of demographic parameters indicated a recent split, with similar fractions of the ancestral pathogen population founding both the rice- and the maize-infecting populations $\left(s_{\text {rice }}=0.47\right.$, with a corresponding $\left.(1-s)_{\text {maize }}=0.53\right)$. The $\theta$ and migration estimates were similar for IM and
MIGRATE. The IM analyses indicated that the maize-infecting population diverged from the rice-infecting population $\approx 110$ years ago $\left(t_{\min }=39\right.$ and $t_{\max }=243$ years $)$.

Cross-pathogenicity test. The rice- and the maize-derived isolates of $R$. solani AG-1 IA were all cross-pathogenic to both maize and rice. However, isolates were more aggressive on their host of origin (significant contrasts of means between maize and rice groups at $P \leq 0.001$ ) (Table 4 ).

\section{DISCUSSION}

Genetic divergence between maize- and rice-infecting populations. To test the hypothesis of no subdivision between different host populations of $R$. solani AG-1 IA within the Poacea group, we sampled sympatric maize and rice fields in three different locations in Venezuela and allopatric rice-infecting populations from Colombia and Panama. Despite the relatively recent emergence of the BLSB disease on maize, significant population subdivision was found between maize- and riceinfecting populations, both in sympatry $\left(\Phi_{S T}=0.14\right.$ to 0.22$)$ and in allopatry $\left(\Phi_{S T}=0.19\right.$ to 0.35$)$. In contrast, significantly less subdivision $\left(\Phi_{S T}=0.03\right.$ to 0.04$)$ was observed among riceinfecting populations and between two of the maize-infecting populations $\left(\Phi_{S T}=0.07\right.$ to 0.08$)$. Thus, we rejected the hypothesis of no subdivision between maize- and rice-infecting host populations of $R$. solani AG-1 IA.

Two results from our study supported a postulated mutation or drift equilibrium, an a priori assumption for analyzing patterns of historical gene flow among populations. (i) We showed that detectable population structure has arisen among allopatric riceinfecting populations from Latin America, consistent with isolation by distance (i.e., limited long-distance [regional] gene flow). (ii) There was no evidence for significant population size change. These two observations, together with information about the history of the diseases on rice and maize in the three countries, indicate that the three regional riceinfecting populations and the maize-infecting populations of $R$. solani AG-1 IA are likely close to migration or drift equilibrium conditions.

We found evidence for symmetrical historical migration between the sympatric rice- and maize-infecting populations, suggesting historical exchange of migrants and only recent emergence of subdivision between sympatric rice- and maize-infecting populations in Venezuela. In comparison with the allopatric riceinfecting populations from Colombia and Panama, the Venezuelan rice-infecting population contributed three times as many migrants to the sympatric maize-infecting population. Maize- and rice-derived isolates of $R$. solani AG-1 IA with different MLMGs were cross-pathogenic to both rice and maize but were more aggressive on their original host. This differential response in aggressiveness toward the two sympatric host populations is consistent with ecological adaptation to either maize or rice $(30,35)$, as recently reported for sympatric rice- and soybeaninfecting populations of $R$. solani AG-1 IA in Louisiana in the United States (6). The extent of genetic differentiation between pathogen populations likely depends on the degree of relatedness of the hosts of origin. For example, when the sympatric rice- and soybean-infecting populations of $R$. solani AG-1 IA from Louisiana were compared, the extent of differentiation was much higher $(\Phi=0.39$ to 0.40$)$ (6) than observed in this study $(\Phi=$ 0.17 to 0.22 ), which included populations from two grass hosts. Maize displaced rice crops in areas not appropriate for rice cropping in Portuguesa State when $R$. solani AG1-IA was already considered endemic on rice (13); therefore, it is likely that the maize-infecting population is derived from a rice-infecting population of $R$. solani AG1-IA.

Time scales for emergence can differ considerably among plant pathogens but emergence through host shifts can occur very 

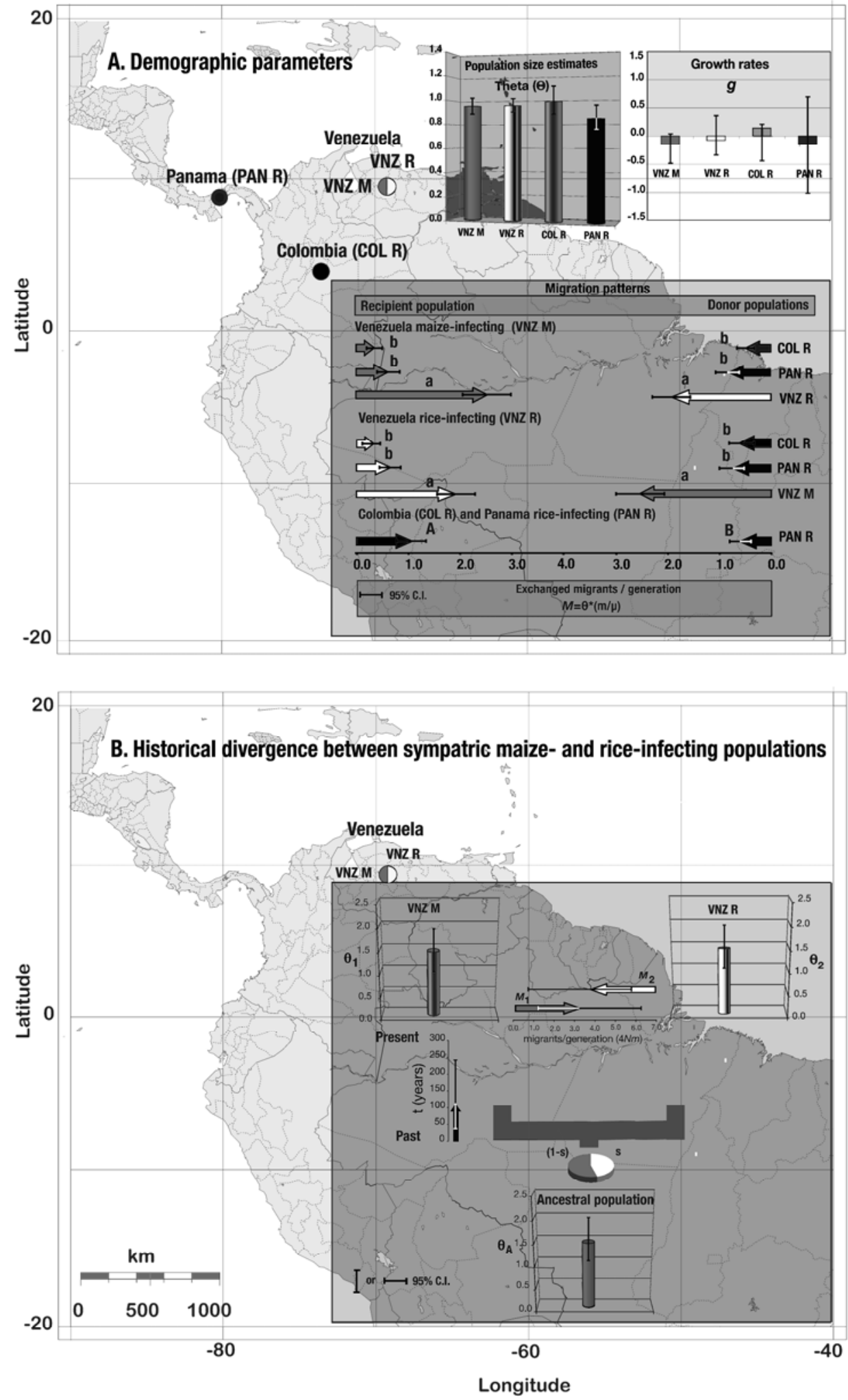

Fig. 2. Estimates of demographic parameters from the divergence among sympatric rice- and maize-infecting populations of Rhizoctonia solani anastomosis group (AG)-1 IA from Venezuela and allopatric rice-infecting populations from Latin America based on variation at 10 microsatellite loci. A, Demographic parameters. Theta $(\theta)$ values represent a measure of effective population size (for diploids $\theta=4 N_{\mathrm{e}} \mu$, where $N_{\mathrm{e}}=$ effective population size and $\mu=$ mutation rate for each locus). Most probable estimates of the exponential population growth rate $(g)$ were calculated by Bayesian analyses using the program LAMARC v.2.1.3. Migration between host populations was estimated using an isolation-with-migration model implemented in MIGRATE v.3.0.3. Migration model with the maximum likelihood $[\operatorname{Ln}(\mathrm{L})=117.4]$ among five independent replicates. All $\theta$ and $M$ values are significantly different from zero based on likelihood ratio tests (LRTs). Migration rates followed by the same letter are not significantly different, based on LRT (original $\alpha=0.05$ lowered to $\alpha \leq 0.0025$, after Bonferroni correction for multiple comparisons). Parameters estimates are with 95\% confidence intervals indicated by vertical (for $\theta$ and $g$ ) or horizontal bars (for $M$ migration rates). B, Historical divergence between sympatric maize- and rice-infecting populations determined using IM. Estimates of $\theta_{\mathrm{A}}, \theta_{1}, \theta_{2}, M$, the splitting parameter $(s)$, and the divergence time $(t)$ are with $95 \%$ confidence intervals indicated by vertical or horizontal bars. We assumed constant population size since divergence and equal population sizes for both maize-infecting $\left(\theta_{1}\right)$ and rice-infecting $\left(\theta_{2}\right)$ populations of the pathogen (i.e., $\theta_{\mathrm{A}}=\theta_{1}=\theta_{2}$ ). 
rapidly (65). Host shift is defined as pathogen adaptation to a new host that is not genetically distant from the original host (65) (e.g., the two Poaceae hosts from this study). Because the maizeand rice-infecting populations are still cross-pathogenic, we postulate that the genetic divergence could be relatively recent. In fact, estimates of divergence time based on these microsatellite loci indicated that the maize-infecting population diverged from the rice-infecting population between 40 and 240 years ago. Under the scenario of a more recent divergence $(\approx 40$ years ago), we postulate that adaptation of $R$. solani AG-1 IA to maize started when maize began to displace rice in rain-fed upland areas that were already infested with the pathogen inoculum. The rate of divergence may have increased over the past few decades due to continuous monoculture of maize. A less recent scenario $(\approx 240$ years ago) places the population divergence at least two centuries after the first introduction of rice cropping into Venezuela by the Spanish settlers (67). Although we lack historical records providing evidence for possible rotations between rice and maize crops earlier than the mid-twentieth century, this could be also a plausible scenario.

Divergence could have been driven by different environmental factors, including the specialized cropping system of each host (e.g., rice is cropped under paddy conditions and maize on dry land) $(12,13,54)$. Divergence could also have occurred if the maize-infecting populations originated from another crop or location and were not descended from local rice-infecting populations in Venezuela. We rejected the latter hypothesis because the maize- and the rice-infecting populations shared similar fractions of the ancestor population. The latter scenario also seems unlikely because BLSB disease on maize has been reported only since the mid-1990s in Venezuela, when maize was introduced into areas formerly cropped with rice $(12,13,54)$, and no report exists supporting the anthropogenic introduction of the pathogen into the country (e.g., by trading infested seed).

The most probable mechanism for the local emergence (in Portuguesa State, Venezuela) of a very serious maize disease (BLSB) is through host shift. Although locally described, the emergence of a new maize pathogen in Venezuela's agroecosystem via host shift is internationally relevant. Devastating epidemics of BLSB have been reported from Bhutan, India, Indonesia, Nepal, Philippines, southern China, Vietnam, Africa, and other Latin American countries $(53,54,73)$. The emergence of the BLSB disease on maize in all these countries, which traditionally grow rice, is unlikely to be a coincidence. We postulate that the independent emergence of BLSB in agroecosystems around the world likely followed a host shift mechanism similar to the one we described in Venezuela.

Stukenbrock and McDonald (65) proposed three factors as the main drivers of pathogen emergence in agroecosystems: (i) the highly homogeneous environment of agroecosystems that is conducive for propagation, dispersal, and the evolution of pathogen virulence; (ii) the vast scale of agroecosystems, resulting in correspondingly large pathogen population sizes; and (iii) the global expansion of trade in agricultural commodities and germplasm, often associated with inefficient quarantine and monitoring systems. The first two factors probably explain the emergence of the maize-specialized populations of the BLSB pathogen. The third factor justifies quarantine measures to confine the pathogen to the area where it emerged. Although $R$. solani AG-1 IA has already emerged as an important maize pathogen in several countries, mainly in Asia, quarantine measures will likely be needed to limit the spread of the maize-specialized populations

TABLE 4. Cross-pathogenicity test of rice- and maize-infecting isolates from distinct multilocus simple sequence repeat (SSR) genotypes of Rhizoctonia solani anastomosis group 1 IA from Venezuela ${ }^{\mathrm{x}}$

\begin{tabular}{|c|c|c|c|c|c|c|c|c|}
\hline Origin & $\begin{array}{c}\text { Multilocus } \\
\text { SSR } \\
\text { genotype }^{y}\end{array}$ & Isolate & \multicolumn{6}{|c|}{ Aggressiveness on two Poaceae hosts ${ }^{\mathrm{z}}$} \\
\hline \multirow[t]{6}{*}{ Maize-infecting isolates } & 129 & M2B1 & \multicolumn{3}{|c|}{6.8} & \multicolumn{3}{|c|}{9.0} \\
\hline & 134 & M1H1 & \multicolumn{3}{|c|}{6.5} & \multicolumn{3}{|c|}{8.4} \\
\hline & 140 & $\mathrm{M} 1 \mathrm{~J} 3$ & \multicolumn{3}{|c|}{6.0} & \multicolumn{3}{|c|}{9.0} \\
\hline & 147 & M2D4 & \multicolumn{3}{|c|}{8.1} & \multicolumn{3}{|c|}{9.0} \\
\hline & 152 & M3D1 & \multicolumn{3}{|c|}{6.3} & \multicolumn{3}{|c|}{9.0} \\
\hline & 168 & M4A5 & \multicolumn{3}{|c|}{6.1} & \multicolumn{3}{|c|}{8.5} \\
\hline All maize-infecting & & & \multicolumn{3}{|c|}{6.3} & \multicolumn{3}{|c|}{8.9} \\
\hline \multirow[t]{6}{*}{ Rice-infecting isolates } & 43 & A1A3 & \multicolumn{3}{|c|}{8.4} & \multicolumn{3}{|c|}{5.3} \\
\hline & 44 & A1A5 & \multicolumn{3}{|c|}{8.2} & & 6.6 & \\
\hline & 48 & $\mathrm{~A} 1 \mathrm{~F} 2$ & & 7.6 & & & 4.9 & \\
\hline & 60 & $\mathrm{~A} 2 \mathrm{C} 2$ & & 7.9 & & & 5.5 & \\
\hline & 64 & A5B4 & & 8.4 & & & 5.1 & \\
\hline & 117 & A6D3 & & 7.7 & & & 5.9 & \\
\hline All rice-infecting & & & & 8.0 & & & 5.4 & \\
\hline All isolates & & & & 7.2 & & & 7.1 & \\
\hline Noninoculated & & & & 0.0 & & & 0.0 & \\
\hline Contrasts & & & Estimate & $F$ values & $P$ & Estimate & $F$ values & $P$ \\
\hline Inoculated versus noninoculated & & & 136.93 & 68.5 & $<0.0001$ & 134.05 & 178.2 & $<0.001$ \\
\hline Maize versus rice isolates & & & -14.88 & 17.3 & 0.0001 & 31.12 & 205.7 & $<0.001$ \\
\hline
\end{tabular}

${ }^{\mathrm{x}}$ Rice and maize experiments were conducted independently. Experiments were arranged in a completely randomized design, with three and four replicates for rice and maize, respectively. Shading indicates mean disease index for each group of isolates.

y Origin of isolates and multilocus SSR genotype. Two sets of host-associated multilocus SSR genotypes yielded a pairwise $\Phi_{\text {ST }}$ maize versus rice $=0.099, P \leq$ 0.01 , indicating significant genetic divergence.

${ }^{\mathrm{z}}$ Disease was scored using an index based on the ratio between the length of typical rice sheath blight or maize banded leaf and sheath blight lesions and plant height $(32,56)$. 
of the fungus to other important maize-growing areas, such as in Australia, Brazil, Europe, and North America.

A mixed reproduction system. The first evidence for recombination was based on the exact test of HWE (19). The maizeinfecting populations had 80 to $100 \%$ of loci with HWE expected proportions, consistent with sexual production, suggesting that basidiospores may play an important role in the epidemiology of the maize BLSB disease. In Venezuela, only the Turén riceinfecting population had the signature of recombination $(78 \%$ of loci in HWE). The rice-infecting population from Panama had $70 \%$ of loci in HWE. High levels of GE provided additional evidence for recombination. GE was very high (92 to $100 \%$ of the locus-pairs) in all maize-infecting populations and in the riceinfecting population from Turén. A very different population structure was observed for the rice-infecting populations from Santa Rosalía and Esteller. After clone correction, these two populations showed a nonrecombining population structure, with a lower proportion of loci in HWE (40 to $55 \%$ of the loci) and a moderate degree of gametic disequilibrium (35 to 39\% of the locus pairs with significant GD). The same pattern was observed for the allopatric rice-infecting population from Colombia.

We investigated the roles of population admixture and nonrandom mating as possible causes for the observed departure from HWE and GD in the rice-infecting populations from Santa Rosalía and Esteller in Venezuela. After removing admixed genotypes, the proportion of loci under HWE expectations increased for both populations (Table 3). GD also fell in the population from Santa Rosalía (as measured by $I_{A}$ and the proportion of locus pairs in GD) but not in the population from Esteller. Our interpretation was that admixture had contributed to but was not the sole explanation for the observed disequilibrium. We could not explore admixture as one of the causes for departure from HWE in Colombia because there were no other Colombian sympatric populations available for comparison. The other plausible cause for the disequilibrium was inbreeding (assortative mating). Significant and positive $F_{I S}$ values were found for Esteller $\left(F_{I S}=0.27\right)$ in Venezuela and also for the population from Panama $\left(F_{I S}=0.43\right)$, suggesting that these populations exhibited a significant degree of inbreeding within the sexual component of reproduction. Although inbreeding does not necessarily indicate a homothallic mating system for the fungus, it could be the first evidence for homothallism in $R$. solani AG-1 IA.

Our interpretation of these findings was that the maize-infecting populations of $R$. solani AG-1 IA in Venezuela regularly undergo sexual recombination, while the occurrence of recombination in the rice-infecting populations from Latin America was population dependent. Taking all of these results together, we propose a mainly recombining reproductive mode for the maizeinfecting populations and a mixed reproductive mode for the riceinfecting populations, which includes recombination events followed by clonal expansion during the growing season.

According to the risk model framework proposed by McDonald and Linde $(41,42)$, the characteristics of high genetic diversity, high gene flow, and the evidence of a mixed reproductive system place rice- and maize-infecting populations of $R$. solani AG-1 IA among pathogens with a very high evolutionary potential. For these pathogens, major resistance genes and fungicides that target a single protein or biochemical pathway should be used with caution. Measures to minimize gene flow among populations (e.g., by reducing the spread of sclerotia via shared irrigation systems or contaminated machinery) are also strongly recommended.

\section{ACKNOWLEDGEMENTS}

A. D. González-Vera acknowledges DANAC (Fundación para la Investigación Agrícola) and FONACIT (Fondo Nacional de Ciencia Tecnología e Innovación), both from Venezuela, for supporting him with a research assistantship during his Ph.D. program and a leave of absence to carry out his research at the IBZ Plant Pathology (ETH Zürich) in 2005. The microsatellite data were collected using the facilities of the Genetic Diversity Center at the ETH. The statistical analyses on migration patterns and demographic parameters estimates by MIGRATE v.3.0.3 and IM were carried out by using the resources of the Computational Biology Service Unit from Cornell University (http:// cbsuapps.tc.cornell.edu/index.aspx), which is partially funded by Microsoft Corporation. The estimates of population growth rates using LAMARC v.2.1.3 were carried out on the freely available bioinformatics Bioportal at University of Oslo (www.bioportal.uio.no). This work was partially funded by an ETH grant (TH-16/06-1) to P. C. Ceresini.

\section{LITERATURE CITED}

1. Adams, G. C. 1996. Genetics of Rhizoctonia species. Page 101-106 in: Rhizoctonia species: Taxonomy, Molecular Biology, Ecology, Pathology and Disease control Kluwer Academic, Dordrecht, The Netherlands.

2. Agapow, P.-M., and Burt, A. 2001. Indices of multilocus linkage disequilibrium. Mol. Ecol. Notes 1:101-102.

3. Amos, W., Hoffman, J. I., Frodsham, A., Zhang, L., Best, S., and Hill, A. V. S. 2007. Automated binning of microsatellite alleles: Problems and solutions. Mol. Ecol. Notes 7:10-14.

4. Beerli, P., and Felsenstein, J. 1999. Maximum-likelihood estimation of migration rates and effective population numbers in two populations using a coalescent approach. Genetics 152:763-773.

5. Beerli, P., and Felsenstein, J. 2001. Maximum likelihood estimation of a migration matrix and effective population sizes in $\mathrm{n}$ subpopulations by using a coalescent approach. PNAS 98:4563-4568.

6. Bernardes de Assis, J., Peyer, P., Zala, M., Rush, M., McDonald, B. A., and Ceresini, P. C. 2008. Divergence between sympatric rice- and soybean-infecting populations of Rhizoctonia solani AG-1 IA Phytopathology 98:1326-1333.

7. Bernardes de Assis, J., Storari, M., Zala, M., Wang, W., Jiang, D., Shidong, L., Jin, M., McDonald, B. A., and Ceresini, P. C. 2008. Population genetics of the rice-infecting pathogen Rhizoctonia solani AG1 IA from its putative center of origin in China and India. Page 4 in: Abstr. 4th Int. Rhizoctonia Symp. Humboldt Universitaet, Berlin.

8. Bernardes de Assis, J., Storari, M., Zala, M., Wang, W., Jiang, D., Shidong, L., Jin, M., McDonald, B. A., and Ceresini, P. C. 2009. Genetic structure of populations of the rice-infecting pathogen Rhizoctonia solani AG-1 IA from China. Phytopathology 99:1090-1099.

9. Bonferroni, C. E. 1935. Il calcolo delle assicurazioni su gruppi di teste. Page 13-60 in: Studi in Onore del Professore Salvatore Ortu Carboni, Rome.

10. Brown, A. H. D., Feldman, M. W., and Nevo, E. 1980. Multilocus structure of natural populations of Hordeum spontaneum. Genetics 96:523-536.

11. Cabrera, S. 2002. Prácticas de manejo para el control de la mancha bandeada de la hoja (Rhizoctonia solani)—determinación de los niveles de incidencia, severidad y efecto sobre el peso de la mazorca en siembras comerciales de maíz. Page 315-334 in: VII Curso sobre Producción de Maíz. Instituto Nacional de Investigaciones Agrícolas-INIA/CIAE, ed. INIA/CIAE, Acarigua.

12. Cardona, R., Rodríguez, H., and Nass, H. 1999. Mancha bandeada en maíz causada por Rhizoctonia solani en el estado Portuguesa, Venezuela. Fitopatol. Venez. 12:32-33.

13. Cedeño, L., Nass, H., Carrero, C., Cardona, R., Rodríguez, H., and Alemán, L. 1996. Rhizoctonia solani AG-1-IA, causa principal del añublo de la vaina del arroz en Venezuela. Fitopatol. Venez. 9:6-9.

14. Ceresini, P. C., Shew, H. D., James, T. Y., Vilgalys, R. J., and Cubeta, M. A. 2007. Phylogeography of the solanaceae-infecting Basidiomycota fungus Rhizoctonia solani AG-3 based on sequence analysis of two nuclear DNA loci. BMC Evol. Biol. 7:163.

15. Ciampi, M. B., Meyer, M. C., Costa, M. J. N., Zala, M., McDonald, B. A., and Ceresini, P. C. 2008. Genetic structure of populations of Rhizoctonia solani anastomosis group-1 IA from soybean in Brazil. Phytopathology 98:932-941.

16. Dettman, J. R., and Taylor, J. W. 2004. Mutation and evolution of microsatellite loci in Neurospora. Genetics 168:1231-1248.

17. El Mousadik, A., and Petit, R. J. 1996. High level of genetic differentiation for allelic richness among populations of the argan tree [Argania spinosa (L.) Skeels] endemic to Morocco. Theor. Appl. Genet. 92:832839.

18. Excoffier, L., Laval, G., and Schneider, S. 2005. Arlequin (version 3.0): An integrated software package for population genetics data analysis. Evol. Bioinf. Online 1:47-50.

19. Falconer, D. S., and Mackay, T. F. C. 1996. Introduction to Quantitative Genetics, 4th ed. Longmans Green, Harlow, Essex, U.K.

20. Fontana, H., and González, C. 2000. El maíz em Venezuela, 1st ed. 
Fundación Polar, Caracas, Venezuela.

21. Godoy-Lutz, G., Kuninaga, S., Steadman, J. R., and Powers, K. 2008. Phylogenetic analysis of Rhizoctonia solani subgroups associated with web blight symptoms on common bean based on ITS-5.8S rDNA. J. Gen. Plant Pathol. 74:32-40.

22. González, C. 2000. El maíz en Venezuela. H. Fontana and C. González, eds. Fundación para la Investigación Agrícola-Danac and Fundación Polar, Caracas, Venezuela.

23. Gonzalez, D., Carling, D. E., Kuninaga, S., Vilgalys, R., and Cubeta, M. A. 2001. Ribosomal DNA systematics of Ceratobasidium and Thanatephorus with Rhizoctonia anamorphs. Mycologia 93:1138-1150.

24. Goudet, J. 1995. FSTAT (version 1.2): A computer program to calculate F-statistics J. Hered. 86:485-486.

25. Grunwald, N. J., Goodwin, S. B., Milgroom, M. G., and Fry, W. E. 2003. Analysis of genotypic diversity data for populations of microorganisms. Phytopathology 93:738-746.

26. Guo, S. W., and Thompson, E. A. 1992. Performing the exact test of Hardy-Weinberg proportions for multiple alleles. Biometrics 48:361-372.

27. Hashiba, T., and Kobayashi, T. 1996. Rice diseases incited by Rhizoctonia species. Page 331-340 in: Rhizoctonia Species: Taxonomy, Molecular Biology, Ecology, Pathology and Disease Control. B. Sneh, S. JabajiHare, S. Neate, and G. Dijst, eds. Kluwer Academic, Dordrecht, The Netherlands

28. Hey, J. 2005. On the number of New World founders: A population genetic portrait of the peopling of the Americas. PLoS Biol. 3:193.

29. Hurlbert, S. 1971. The nonconcept of species diversity: A critique and alternative parameters. Ecology 52:577-586.

30. Huyse, T., Poulin, R., and Theron, A. 2005. Speciation in parasites: a population genetics approach. Trends Parasitol. 21:469-475.

31. INE. 2001. Portuguesa-Síntesis Estadística-2001. Instituto Nacional de Estadística, ed. INE, Caracas, Venezuela.

32. Jia, Y., Correa-Victoria, F., McClung, A., Zhu, L., Liu, G., Wamishe, Y., Xie, J., Marchetti, M., Pinson, S. R. M., Rutger, J. N., and Correll, J. C. 2007. Rapid determination of rice cultivar responses to the sheath blight pathogen Rhizoctonia solani using micro-chamber screening method. Plant Dis. 91:485-489.

33. Jones, R. K., and Belmar, S. B. 1989. Characterization and pathogenicity of Rhizoctonia spp. isolated from rice, soybean, and other crops grown in rotation with rice in Texas. Plant Dis. 73:1004-1010.

34. Ko, W., and Hora, F. 1971. A selective medium for the quantitative determination of Rhizoctonia solani in soil. Phytopathology 61:707-710.

35. Kohn, L. M. 2005. Mechanisms of fungal speciation. Annu. Rev. Phytopathol. 43:279-308.

36. Kuhner, M. K. 2006. Lamarc 2.0: Maximum likelihood and Bayesian estimation of population parameters. Bioinformatics 22:768-770.

37. Kuhner, M. K., and Smith, L. P. 2007. Comparing likelihood and Bayesian coalescent estimation of population parameters. Genetics 175:155-165.

38. Linde, C. C., Zala, M., Paulraj, R. S. D., McDonald, B. A., and Gnanamanickam, S. S. 2005. Population structure of the rice sheath blight pathogen Rhizoctonia solani AG-1 IA from India. Eur. J. Plant Pathol. 112:113-121.

39. Malaguti, G. 1951. Mancha de la hoja envainadora del arroz causada por Rhizoctonia solani. Agron. Trop. 1:71-75.

40. Mantel, N. A. 1967. The detection of disease clustering and a generalized regression approach. Cancer Res. 27:209.

41. McDonald, B. A., and Linde, C. 2002. Pathogen population genetics, evolutionary potential, and durable resistance. Annu. Rev. Phytopathol. 40:349-379.

42. McDonald, B. A., and Linde, C. 2002. The population genetics of plant pathogens and breeding strategies for durable resistance. Euphytica 124:163-180.

43. Meirmans, P. G., and Van Tienderen, P. H. 2004. GenoType and GenoDive: Two programs for the analysis of genetic diversity of asexual organisms. Mol. Ecol. Notes 4:792-794.

44. Ministerio de Agricultura y Cría. 1937. Memoria del Ministerio de Agricultura y Cría presentada a las cámaras legislativas de los Estados Unidos de Venezuela en 1937. Ministerio de Salubridad y de Agricultura y Cría, ed. Cooperativa de Artes Gráficas, Caracas, Venezuela.

45. Ministerio de Fomento. 1962. II Censo Agropecuario de 1950. Dirección General de Estadística y Censos Nacionales, ed. Ministerio de Fomento, Caracas, Venezuela.
46. Naito, S. 1996. Basidiospore dispersal and survival. Page 197-206 in: Rhizoctonia Species: Taxonomy, Molecular Biology, Ecology, Pathology and Disease Control. Kluwer Academic, Dordrecht, The Netherlands.

47. Naito, S. 2006. Ecological studies on teleomorphic and anamorphic stages in Rhizoctonia fungi. J. Gen. Plant Pathol. 72:400-403.

48. Nei, M. 1978. Estimation of average heterozygosity and genetic distance from a number of individuals. Genetics 89:538-590.

49. Nielsen, R., and Wakeley, J. 2001. Distinguishing migration from isolation: A Markov chain Monte Carlo approach. Genetics 158:885-896.

50. Ogoshi, A. 1987. Ecology and pathogenicity of anastomosis and intraspecific groups of Rhizoctonia solani Kühn. Annu. Rev. Phytopathol. 25:125-143.

51. Oniki, M., Ogoshi, A., and Araki, T. 1986. Development of the perfect state of Rhizoctonia solani Kühn AG-1. Ann. Phytopathol. Soc. Jpn. 52:169-74.

52. Parker, I. M., and Gilbert, G. S. 2004. The evolutionary ecology of novel plant-pathogen interactions. Annu. Rev. Ecol. Evol. Soc. 35:675-700.

53. Pascual, C. B., and Hyakumachi, M. 2000. Distribution of vegetatively compatible populations of Rhizoctonia solani AG-1 IA in a field planted with different host species. J. Gen. Plant Pathol. 66:206-209.

54. Perdomo, R., Hernández, A., Gonzáles, A., Pineda, J., and Alezones, J. 2007. Caracterización y evaluación de virulencia en aislamientos de Rhizoctonia solani Kühn, causante de la mancha bandeada en maíz. Interciencia 32:48-55.

55. Petit, R. J., El Mousadik, A., and Pons, O. 1998. Identifying populations for conservation on the basis of genetic markers. Conserv. Biol. 12:844 855.

56. Pineda, J., Hernández, A., González, A., Barrientos, V., Nass, H., and Gil, E. 2005. Técnica de inoculación rápida y eficiente para la evaluación de materiales de maíz ante Rhizoctonia solani Kühn. Bioagro 17:93-98.

57. Pritchard, J. K., Stephens, M., and Donnelly, P. 2000. Inference of population structure using multilocus genotype data. Genetics 155:945-959.

58. Raymond, M., and Rousset, F. 1995. GenePop (version 1.2): Population genetics software for exact tests and ecumenicism. J. Hered. 86:248-249.

59. Rosewich, U. L., Pettway, R. E., McDonald, B. A., and Kistler, H. C. 1999. High levels of gene flow and heterozygote excess characterize Rhizoctonia solani AG-1 IA (Thanatephorus cucumeris) from Texas. Fungal Genet. Biol. 28:148-159.

60. Rousset, F. 1997. Genetic differentiation and estimation of gene flow from F-statistics under isolation by distance. Genetics 145:1219-1228.

61. Slatkin, M. 1995. A measure of population subdivision based on microsatellite allele frequencies. Genetics 139:457-462.

62. Sneh, B., Jabaji-Hare, S., Neate, S., and Dijst, G. 1996. Rhizoctonia species: Taxonomy, Molecular Biology, Ecology, Pathology and Disease Control. Kluwer Academic Publishers, Dordrecht, The Netherlands.

63. Stoddart, J. A. 1983. A genotypic diversity measure. J. Hered. 74:489-490.

64. Stoddart, J. A., and Taylor, J. F. 1988. Genotype diversity: Estimation and prediction in samples. Genetics 118:705-711.

65. Stukenbrock, E. H., and McDonald, B. A. 2008. The origins of plant pathogens in agro-ecosystems. Annu. Rev. Phytopathol. 46:75-100.

66. Van Der Merwe, N., Cornetius, A., and Voguel, J. 1981. Isotopic evidence for prehistoric subsistence change at Parmana, Venezuela. Nature 292:536-538.

67. Velásquez de Alonso, L., Sanchez R., M., Alonso C., J., and de Pasquali., R. H. 2005. Portuguesa Pueblo y Tierra: 2.500 Anos de Historia, 1st ed. Editores Educativos Candidus, Valencia

68. Vitalis, R., Dawson, K., and Boursot, P. 2001. Interpretation of variation across marker loci as evidence of selection. Genetics 158:1811-1823.

69. Vitalis, R., Dawson, K., Boursot, P., and Belkhir, K. 2003. DetSel 1.0: A computer program to detect markers responding to selection. J. Hered. 94:429-431.

70. Weir, B. S. 1996. Genetic Data Analysis, 2nd ed. Sinauer, Sunderland, MA.

71. Wright, S. 1965. The interpretation of population structure by F-statistics with special regard to systems of mating. Evolution:395-420.

72. Zala, M., McDonald, B. A., Bernardes de Assis, J., Ciampi, M. B., Storari, M., Peyer, P., and Ceresini, P. C. 2008. Highly polymorphic microsatellite loci in the maize- and rice-infecting fungal pathogen Rhizoctonia solani anastomosis group 1 IA. Mol. Ecol. Resour. 8:686-689.

73. Zhao, M., Zhang, Z., Zhang, S., Li, W., Jeffers, D. P., Rong, T., and Pan, G. 2006. Quantitative trait loci for resistance to banded leaf and sheath blight in maize. Crop Sci. 46:1039-1045. 